\title{
Rectal Mycoplasma genitalium in Patients Attending Sexually Transmitted Disease Clinics in China: An Infection That Cannot Be Ignored
}

\author{
Yan Han ${ }^{1,2}$ \\ Yue-Ping Yin (iD) ${ }^{1,2}$ \\ Jing-Wei Liu (D) 1,2 \\ Kai Chen ${ }^{1,2}$ \\ Bang-Yong Zhu ${ }^{3}$ \\ Ke Zhou ${ }^{1,2}$ \\ Mei-Qin Shi, ${ }^{1,2}$ \\ Wen-Qi Xu ${ }^{l, 2}$ \\ Tulip A Jhaveri ${ }^{4}$ \\ Xiang-Sheng Chen (D) ${ }^{1,2}$ \\ 'Institute of Dermatology, Chinese \\ Academy of Medical Sciences and Peking \\ Union Medical College, Nanjing, People's \\ Republic of China; ${ }^{2}$ National Center for \\ STD Control, Chinese Center for \\ Disease Control and Prevention, Nanjing, \\ People's Republic of China; ${ }^{3}$ Institute of \\ Dermatology, Guangxi Autonomous \\ Region, Nanning, People's Republic of \\ China; ${ }^{4}$ Division of Medical Microbiology, \\ Department of Pathology, Brigham and \\ Women's Hospital, Harvard Medical \\ School, Boston, MA, USA
}

Background: Previous studies have investigated rectal Mycoplasma genitalium (MG) in men who have sex with men (MSM), while little is known about the prevalence of rectal MG infection in individuals attending sexually transmitted disease (STD) clinics in China. We aimed to estimate the prevalence of rectal $\mathrm{MG}$ infection in this population and identified the potential risk factors for rectal MG infection.

Methods: A cross-sectional study was conducted among individuals attending STD clinics located in China from June 2018 to August 2020. Univariate and multivariate logistic regression analyses were conducted to explore the association of different risk factors for rectal MG infection.

Results: A total of 1,382 patients were included in the final analyses. A total of 30 of 1377 rectal swabs $(2.2 \%)$ and 77 of 1374 urogenital samples $(5.6 \%)$ were positive for MG. In Guangxi, 18 of 47 patients (38.3\%) infected with urogenital MG and 5 of 19 patients $(26.3 \%)$ infected with rectal MG received the recommended treatment. Factors found to be significantly associated with rectal MG infection included: male (adjusted odds ratio (AOR) 0.232, [95\% CI: 0.072-0.745]) compared to female, homosexual or bisexual (AOR 40.427, [95\% CI: 3.880-421.196]) compared to heterosexual, and those infected with urogenital MG (AOR 7.215, [95\% CI: 2.898-17.965]) compared to those who did not get infected with urogenital MG.

Conclusion: Rectal MG infection should be thought of not only in MSM population but also in STD clinic patients, especially females who have urogenital MG infection. Appropriate strategy for rectal MG screening and treatment needs to be developed for these patients in China.

Keywords: Mycoplasma genitalium, rectal infection, sexually transmitted disease clinics

\section{Plain Language Summary}

Mycoplasma genitalium (MG) infection is recognized as a challenging sexually transmitted disease (STD). More studies have investigated rectal MG in men who have sex with men (MSM), while little is known about the prevalence of rectal MG infection in individuals attending sexually transmitted disease (STD) clinics in China. In this study, we conducted a cross-section study to assess the prevalence of rectal MG infection in this population and identified the potential risk factors for rectal MG infection. The prevalence of rectal MG infection was $2.2 \%(30 / 1377)$ among this population while most of them did not receive the recommended treatment. The female patients, homosexual or bisexual patients or patients with urogenital MG were prone to infect with rectal MG. Screening for rectal MG infection should be considered in individuals attending STD clinics, especially in females who have
Correspondence: Yue-Ping Yin Institute of Dermatology, Chinese Academy of Medical Sciences and Peking Union Medical College, 12 Jiangwangmiao Street, Nanjing, 210042, People's Republic of China

Tel/Fax +862585478024

Email yinyp@ncstdlc.org 
urogenital MG infection. An appropriate strategy for rectal MG treatment needs to be developed for these patients.

\section{Introduction}

Mycoplasma genitalium (MG) infection is recognized as a challenging sexually transmitted disease (STD). ${ }^{1}$ The prevalence of $\mathrm{MG}$ in general population aged 16 to 44 years is $1-2 \%$, 2,3 only slightly lower than the most prevalent STD - Chlamydia trachomatis (CT). ${ }^{2}$ The rates of MG infection in men who have sex with men (MSM) $(3.2 \%)$, sex workers $(15.9 \%){ }^{4}$ and STD clinic attendees presenting with symptomatic urethritis $(19.7 \%)^{5}$ were higher than the rates in general population. Urogenital MG is reported to be associated with increased risk of urethritis, ${ }^{6}$ cervicitis, pelvic inflammatory disease, and infertility. $^{7}$ Although there is an unclear association between rectal infection and accompanying syndromes such as rectal pain and ulceration, rectal infection could potentially lead to urethral involvement if not detected and treated timely. ${ }^{8}$

Previous studies looked at rectal MG testing in MSM population who had anal intercourse. ${ }^{9-11}$ However, very few studies suggest that rectal $\mathrm{MG}$ is also prevalent in female patients who did not have anal sex. ${ }^{12,13}$ To date, very scant information is available on the rectal prevalence of MG in STD clinic attendees in China. The goals of this study were to (1) determine the prevalence of rectal $\mathrm{MG}$ infections in patients attending STD clinics, (2) identify potential risk factors for rectal $\mathrm{MG}$ infection, and (3) analyze how often patients receive recommended antibiotic treatment for rectal MG by investigating physicians' antibiotic prescriptions. This data would be an effective way to understand the transmission routes of rectal $\mathrm{MG}$ in China and enable us to rethink about the best possible strategy to prevent it.

\section{Materials and Methods Study Participants}

Between June 2018 and August 2020, a cross-sectional study was conducted among attendees from two STD clinics in China - (1) Tianjin Institute of Traditional Chinese Medicine located in northern China, and (2) Guangxi Institute of Dermatology located in southern China. This study was conducted in accordance with the Declaration of Helsinki and approved by the Institutional Review Board of the Institute of Dermatology, the Chinese Academy of Medical Sciences and Peking Union Medical
College (approval number 2017-LS-021). Attendees no less than 18 years of age who signed an informed consent to provide urine, vaginal and rectal swabs were enrolled in the study. Consenting participants were asked to fill out an anonymous questionnaire that consisted of questions regarding socio-demographic characteristics, sexual behavior, and STD history. Information on physicians' prescription was collected from the Institute of Dermatology, Guangxi Autonomous Region.

\section{Specimen Collection}

Approximately $10-15 \mathrm{~mL}$ of first void urine (FVU) was collected by male participants. The technicians transferred $5-7 \mathrm{~mL}$ of urine into the Cobas ${ }^{\circledR}$ PCR Media tube using disposable pipettes (Roche Molecular Systems, New Jersey, USA). Rectal and vaginal swabs were collected and transferred into the Cobas ${ }^{\circledR}$ PCR Media tube by the technicians directly. These media tubes were stored at $4^{\circ} \mathrm{C}$ in the hospitals. They were transported at $18-25^{\circ} \mathrm{C}$ to the STD reference laboratory at the National Center for STD Control.

\section{Laboratory Testing}

Urogenital and rectal CT and Neisseria gonorrhoeae (NG) were examined by the Cobas ${ }^{\circledR} 4800 \mathrm{CT} / \mathrm{NG}$ assay (Roche Molecular Systems, New Jersey, USA) according to the instructions in the STD reference laboratory. Nucleic acid samples were extracted on the Cobas x480 instrument. PCR amplification and detection were fully automated on the Cobas z480 analyzer. The genomic DNA for MG was extracted from urogenital and rectal samples which remained preserved in Cobas ${ }^{\circledR}$ PCR Media tube using Tianlong nucleic acid extraction reagent (Xi'an Tianlong Science \& Technology Co., LTD, Shaanxi, China) in Tianlong GeneRotex 96 nucleic acid extractor according to the manufacturer's instruction. The template DNA amplified the $\mathrm{MgPa}$ adhesion gene by a previous realtime PCR method as described by Jensen et al $^{14}$ with minor modification. The primers for amplification included $\mathrm{MgPa}-355 \mathrm{~F}$ (5'-GAG AAA TAC CTT GAT GGT CAG CAA-3'), MgPa-432R (5'-GTT AAT ATC ATA TAA AGC TCT ACC GTT GTT ATC-3'), and MgPa-380 (5'-HEX-ACT TTG CAA TCA GAA GGTBQ1-3'). Primers and HEX probe were synthesized by Invitrogen Corporation (Invitrogen Corporation, USA). All PCR reactions were performed using a Light-cycler 480 Real-Time PCR System (Roche, Basel, Switzerland) and Cobas x480 instrument (Roche Molecular Systems, 
New Jersey, USA). Each $20 \mu \mathrm{L}$ PCR reaction mixture contained $10 \mu \mathrm{L} 2 \times$ Vazyme Taq HS Probe Master Mix, $0.8 \mu \mathrm{L} \mathrm{MgPa}-355 \mathrm{~F}$ and MgPa-432R, $0.2 \mu \mathrm{L} \mathrm{MgPa}-380,6$ $\mu \mathrm{L}$ Ultra-pure water and $2 \mu \mathrm{L}$ template DNA. Each batch of test included a positive and negative control and were performed under the following conditions: denaturation at $95^{\circ} \mathrm{C}$ for 2 minutes followed by 45 cycles of denaturation at $95^{\circ} \mathrm{C}$ for 15 seconds, annealing at $60^{\circ} \mathrm{C}$ for 35 seconds, and cooling at $37^{\circ} \mathrm{C}$ for 2 minutes.

\section{Data Analysis}

Questionnaires and experimental data were entered into an Excel format database. Descriptive and inferential analyses were performed on the IBM SPSS Statistics for Windows Version 22.0 (IBM Corp, New York, USA). Binary logistic regressions were conducted to explore the associations of different risk factors for MG infection with odds ratio and corresponding 95\% confidence intervals (CI) concurrently estimated. Variables associated with MG at $\mathrm{P} \leq 0.10$ in univariate logistic regressions were included in multivariate logistic regression models to identify independent risk factors. Variables associated with $\mathrm{MG}$ at $\mathrm{P}<0.05$ in multivariate logistic regressions were considered statistically significant.

\section{Results}

A total of 1,563 participants were enrolled during the study period. Fifteen of them did not meet recruitment criteria (age <18), 19 refused to collect rectal swabs, and 147 rectal samples were collected with inappropriate swabs by the sampling nurses. One thousand three hundred and eighty-two participants were included in the final analysis. Two-fifths of $(40.0 \%, \mathrm{n}=553)$ participants were enrolled from Tianjin and $44.4 \%(n=614)$ were male. The average age of participants was 37.9 (ranged from 18 to 72 years old). Two participants reported their sexual orientation as homosexual, and three participants reported their bisexual orientation. Nearly a quarter of patients $(24.9 \%$, $343 / 1379)$ belonged to ethnic minorities, and 23.0\% (318/ 1382) of them were single. Anal intercourse in the past 2 weeks was reported by 4 male patients $(0.7 \%, 4 / 611)$ and 3 female patients $(0.4 \%, 3 / 761)$. Nearly two-third attendees $(67.0 \%, 926 / 1382)$ presented with urogenital symptoms, while none of the recruited participants presented with rectal symptoms.

Of the 1382 patients, male patients provided 612 urine samples and 614 rectal swabs, while female patients provided 768 vaginal and rectal swabs each. PCR amplification could not be performed on 6 urogenital samples and 5 rectal swabs. Among 30 patients infected with rectal $\mathrm{MG}, 4$ patients $(13.3 \%)$ were co-infected with rectal $\mathrm{CT}$ and urogenital MG and CT. The distribution of rectal and urogenital $\mathrm{MG}, \mathrm{CT}$, and $\mathrm{NG}$ among the rectal $\mathrm{MG}$ positive population is shown in Table 1. A total of 30 $(2.2 \%, 30 / 1377,95 \%$ CI $1.5-3.1 \%)$ rectal swabs and 77 (5.6\%, 77/1374, 95\% CI 4.8-7.0\%) urogenital samples were tested positive for MG. The rectal prevalence for CT and NG were $4.9 \%$ (68/1377, 95\% CI 3.9-6.2\%), and $2.5 \%$ (35/1377, 95\% CI 1.8-3.6\%), respectively. The urogenital prevalence for CT and NG were 11.2\% (154/1374 95\% CI 9.6-13.0\%), and 5.7\% (78/1374, 95\% CI 4.5$7.1 \%$ ), respectively (Table 2 ).

Of the 47 urogenital $\mathrm{MG}$ infected patients from the Institute of Dermatology Guangxi Autonomous Region, 18 patients (38.3\%, 95\% CI 24.9-53.6\%) received doxycycline, azithromycin or moxifloxacin which were recommended by National STD Treatment Guidelines for urogenital MG. ${ }^{15}$ Of those who received appropriate treatment, fifteen $(83.3 \%$, 15/18, 95\% CI 57.7-95.6\%) patients had specific presenting

Table I Rectal and Urogenital Distribution of MG, CT, and NG Among the Rectal MG Positive Population

\begin{tabular}{|l|c|c|c|c|c|c|c|}
\hline \multicolumn{2}{|l|}{ Rectal } & \multicolumn{3}{|c|}{ Urogenital } & \multirow{2}{*}{ No } & \multirow{2}{*}{ Proportion } \\
\cline { 1 - 5 } MG & CT & NG & MG & CT & NG & & \\
\hline+ & + & - & + & + & - & 4 & $13.3 \%$ \\
+ & + & - & - & + & - & I & $3.3 \%$ \\
+ & + & - & - & - & + & I & $3.3 \%$ \\
+ & - & + & - & - & + & I & $3.3 \%$ \\
+ & - & - & - & - & - & 14 & $46.7 \%$ \\
+ & - & - & + & - & - & 5 & $16.7 \%$ \\
+ & - & - & + & + & - & I & $3.3 \%$ \\
+ & - & - & - & + & + & I & $3.3 \%$ \\
+ & - & - & N & N & N & I & $3.3 \%$ \\
\hline Total & & & & & & 30 & $100.0 \%$ \\
\hline
\end{tabular}

Abbreviations: MG, Mycoplasma genitalium; CT, Chlamydia trachomatis; NG, Neisseria gonorrhoeae.

Table 2 Prevalence of Anorectal and Urogenital STIs Among STD Clinic Attendees in China

\begin{tabular}{|l|l|l|l|}
\hline & Anorectal & Urogenital & Total \\
\hline MG & $2.2 \%(30 / 1377)$ & $5.6 \%(77 / / 374)$ & $7.2 \%(97 / 1374)$ \\
CT & $4.9 \% 68 / 1377)$ & $11.2 \%(154 / 1374)$ & $12.2 \%(167 / / 374)$ \\
NG & $2.5 \%(35 / / 377)$ & $5.7 \%(78 / / 374)$ & $6.1 \%(84 / 1374)$ \\
\hline
\end{tabular}

Abbreviations: STIs, sexually transmitted infections; STD, sexually transmitted disease; MG, Mycoplasma genitalium; CT, Chlamydia trachomatis; NG, Neisseria gonorrhoeae. 
urogenital complaint or physical examination finding. Four rectal-MG positive patients used antimicrobials before enrollment, and more than $70 \%$ (14/19) did not receive recommended antibiotics after enrollment.

Univariate logistic regression analyses showed that rectal MG was significantly associated with female patients, younger age (age $\leq 30$ years), single marital status, self-reported sexual orientation, lack of medical insurance, low income (less than 80,000 Renminbi Yuan per year), genital symptoms, infection with rectal CT, urogenital CT, and urogenital MG. These variables were selected in the final multivariate analysis. After adjusting for potential confounders, the following four variables were found to be significantly associated with rectal MG: male patients (AOR 0.232, [95\% CI: 0.072-0.745]), homosexual or bisexual orientation (AOR 40.427, [95\% CI: 3.880421.196]), having genital symptoms (AOR 3.495, [95\% CI: $1.160-10.534])$, and infection with urogenital MG (AOR 7.215, [95\% CI: 2.898-17.965]) (Table 3).

\section{Discussion}

Although there is a study published on rectal MG prevalence in Chinese men who have sex with men, ${ }^{11}$ this is the first observational study that describes the rectal prevalence of MG infections in large groups of STD clinic attendees in China. The rectal prevalence of MG was $2.0 \%(11 / 552)$ in the city of Tianjin located in northern China and 2.3\% (19/825) in the city of Nanning located in southern China. The total prevalence of rectal MG in these cities $(2.2 \%, 30 / 1377)$ is less than prevalence of urogenital MG (5.6\%, 77/1374) among STD clinic attendees in our study, similar to the findings seen in the study conducted in female STD clinic attendees enrolled in New Orleans where the prevalence of rectal MG $(4.3 \%, 17 / 398)$ was less than the prevalence of urogenital MG (16.3\%, 65/ 400). ${ }^{16}$ On the contrary, in a study conducted among MSM population, ${ }^{17}$ the total prevalence of rectal MG $\left(6.2 \%, 95 \%\right.$ CI $\left.4.6-8.1 ; \mathrm{I}^{2}=88.1\right)$ was higher than the urogenital MG prevalence $(5.0 \%, 95 \%$ CI $3.5-6.8$; $\left.\mathrm{I}^{2}=94.0\right)$.

Receptive anal intercourse is considered to be the main route for transmission of rectal MG. ${ }^{9}$ In our study, 4 male patients $(0.7 \%, 4 / 564)$ and 3 female patients $(0.4 \%, 3 / 744)$ self-reported having receptive anal intercourse in the past two weeks. The rates of self-reported anal intercourse were quite lower than the rates described in previous studies which were meta-reviewed by Owen et al (African (16.9\%), Asia (14.3\%), and North American
$(22.4 \%)) .{ }^{18}$ Patients who self-reported having anal intercourse in our study were more vulnerable to be infected with rectal MG. The rectal MG prevalence in these patients (14.28\%) was higher than patients who did not receive anal intercourse $(2.01 \%, 27 / 1296$, Fisher exact calculation, $\mathrm{p}=0.141$ ). Patients who self-reported homosexual/bisexual sex had higher rectal MG prevalence $(40 \%, 2 / 5)$ than patients who were heterosexual $(2.0 \%$, 28/1369) with adjusted odds ratio of 40.427 (95\% CI: 3.880-421.196). Patients who have had receptive anal intercourse should be screened for rectal MG infection, and homosexual or bisexual patients should be considered as high-risk groups for rectal MG infection. While there were ten patients (one male and 9 female patients) in this study who had two anatomical sites positive for MG, none of them self-reported having anal receptive intercourse in the past two weeks. Hence, it is possible that rectal MG infection might be acquired from other transmitted routes.

Male patients had lower rectal MG prevalence $(1.0 \%$, $6 / 610)$ than female $(3.1 \%, 24 / 767$; AOR, $0.232 ; 95 \% \mathrm{CI}$ $0.072-0.745$ ) in our study. The female prevalence of rectal MG in our study is comparable to the prevalence in STD clinic-attending women $(4.3 \%, 17 / 398)$ in New Orleans, ${ }^{15}$ but extremely lower than the women at high risk of urogenital CT from Seattle's municipal STD clinic (22\%, 11/ 50). ${ }^{12}$ More than half of $(52.94 \%, 9 / 17)$ female patients with rectal MG infection also had concomitant MG infection at urogenital anatomic site. The phenomenon of high prevalence of concurrent vaginal and rectal MG infection was also found in Khosropour's study. ${ }^{12}$ Multivariate logistic regression analyses also showed that the patients infected with urogenital MG would be more prone to getting infected with rectal MG $(12.7 \%, 8 / 63)$. Above results suggest that rectal $\mathrm{MG}$ infection may either be acquired by auto-inoculation from urogenital tract in female patients similar to that seen in CT infection ${ }^{19}$ or by contamination of the rectal epithelium from urogenital tract due to post-toilet wiping behavior seen in female population. $^{20}$

Nearly two-third patients with rectal MG infection did not have urogenital MG, and all these patients denied having anal intercourse. We bring up the hypothesis that the clearance of rectal infection of MG may be after urogenital MG infection, but the theory of clearance time for MG from different infection sites need to be elucidated by larger population-based studies. Whether the rectal site acts as a reservoir and transmits MG to urogenital site also needs further clarification. 
Table 3 Risk Factors Associated with Increased Risk of Rectal MG Among STD Clinic Attendees in China

\begin{tabular}{|c|c|c|c|c|}
\hline Risk Factors & Levels & Prevalence\%, (no./No.) & $\begin{array}{l}\text { Odds Ratio } \\
\text { OR }(95 \% \mathrm{CI})\end{array}$ & $\begin{array}{l}\text { Adjusted Odds Ratio } \\
\text { AOR }(95 \% \mathrm{CI})\end{array}$ \\
\hline Zone & $\begin{array}{l}\text { Tianjin } \\
\text { Guangxi }\end{array}$ & $\begin{array}{l}2.0 \%(11 / 552) \\
2.3 \%(19 / 825)\end{array}$ & $\begin{array}{l}0.996[0.973-1.018] \\
\text { Reference }\end{array}$ & \\
\hline Gender & $\begin{array}{l}\text { Male } \\
\text { Female }\end{array}$ & $\begin{array}{l}1.0 \%(6 / 610) \\
3.1 \%(24 / 767)\end{array}$ & $\begin{array}{l}0.308[0.125-0.757]^{\#} \\
\text { Reference }\end{array}$ & $\begin{array}{l}0.232[0.072-0.745]^{*} \\
\text { Reference }\end{array}$ \\
\hline Age & $\begin{array}{l}\leq 30 \\
>30\end{array}$ & $\begin{array}{l}4.9 \%(19 / 384) \\
1.1 \%(11 / 993)\end{array}$ & $\begin{array}{l}4.647[2.190-9.860]^{\#} \\
\text { Reference }\end{array}$ & $\begin{array}{l}\text { I.844 }[0.686-4.959] \\
\text { Reference }\end{array}$ \\
\hline Education & $\begin{array}{l}\text { Basic } \\
\text { High }\end{array}$ & $\begin{array}{l}2.1 \%(5 / 234) \\
2.6 \%(12 / 469)\end{array}$ & $\begin{array}{l}0.832[0.289-2.389] \\
\text { Reference }\end{array}$ & \\
\hline Marriage & $\begin{array}{l}\text { Married } \\
\text { Single }\end{array}$ & $\begin{array}{l}4.5 \%(17 / 378) \\
1.3 \%(13 / 999)\end{array}$ & $\begin{array}{l}3.572[1.718-7.427]^{\#} \\
\text { Reference }\end{array}$ & $\begin{array}{l}\mathrm{I} .488[0.554-3.993] \\
\text { Reference }\end{array}$ \\
\hline Ethnicity & $\begin{array}{l}\text { Han } \\
\text { Minority nationality }\end{array}$ & $\begin{array}{l}2.3 \%(24 / 1033) \\
1.7 \%(6 / 343)\end{array}$ & $\begin{array}{l}\text { I.328 }[0.538-3.277] \\
\text { Reference }\end{array}$ & \\
\hline Sexual Orientation & $\begin{array}{l}\text { Homosexual/Bisexual } \\
\text { Heterosexual }\end{array}$ & $\begin{array}{l}40 \%(2 / 5) \\
2.0 \%(28 / 1369)\end{array}$ & $\begin{array}{l}31.929[5.132-198.625]^{\#} \\
\text { Reference }\end{array}$ & $\begin{array}{l}40.427[3.88-421.196]^{*} \\
\text { Reference }\end{array}$ \\
\hline Insurance & $\begin{array}{l}\text { Not-have } \\
\text { Have }\end{array}$ & $\begin{array}{l}3.4 \%(14 / 408) \\
I .5 \%(16 / 965)\end{array}$ & $\begin{array}{l}2.108[1.019-4.359]^{\#} \\
\text { Reference }\end{array}$ & $\begin{array}{l}\text { I.797 [0.779-4.142] } \\
\text { Reference }\end{array}$ \\
\hline Income/year Renminbi Yuan & $\begin{array}{l}<80,000 \\
\geq 80,000\end{array}$ & $\begin{array}{l}2.6 \%(29 / 1096) \\
0.4 \%(1 / 238)\end{array}$ & $\begin{array}{l}6.297[0.854-46.457]^{\#} \\
\text { Reference }\end{array}$ & $\begin{array}{l}5.134[0.634-41.549] \\
\text { Reference }\end{array}$ \\
\hline STD History & $\begin{array}{l}\text { Yes } \\
\text { No }\end{array}$ & $\begin{array}{l}2.1 \%(5 / 239) \\
2.2 \%(25 / 1136)\end{array}$ & $\begin{array}{l}0.950[0.360-2.506] \\
\text { Reference }\end{array}$ & \\
\hline Number of Partners & $\begin{array}{l}>1 \\
=1\end{array}$ & $\begin{array}{l}\text { I.6\% }(5 / 320) \\
2.5 \%(24 / 979)\end{array}$ & $\begin{array}{l}0.637[0.24 I-I .684] \\
\text { Reference }\end{array}$ & \\
\hline Symptoms & $\begin{array}{l}\text { Yes } \\
\text { No }\end{array}$ & $\begin{array}{l}2.8 \%(26 / 923) \\
0.9 \%(4 / 454)\end{array}$ & $\begin{array}{l}3.261[1.131-9.400]^{\#} \\
\text { Reference }\end{array}$ & $\begin{array}{l}3.495[1.160-10.534]^{*} \\
\text { Reference }\end{array}$ \\
\hline Anal Infection & $\begin{array}{l}\text { CT } \\
\text { Non-CT } \\
\text { NG } \\
\text { Non-NG }\end{array}$ & $\begin{array}{l}10.3 \%(7 / 68) \\
1.8 \%(23 / 1309) \\
5.7 \%(2 / 35) \\
2.1 \%(28 / 1342)\end{array}$ & $\begin{array}{l}6.416[2.650-15.534]^{\#} \\
\text { Reference } \\
2.844[0.650-12.439] \\
\text { Reference }\end{array}$ & $\begin{array}{l}2.213[0.445-11.007] \\
\text { Reference }\end{array}$ \\
\hline Urogenital Infection & $\begin{array}{l}\text { CT } \\
\text { Non-CT } \\
\text { NG } \\
\text { Non-NG } \\
\text { MG } \\
\text { Non-MG }\end{array}$ & $\begin{array}{l}5.2 \%(8 / 154) \\
1.7 \%(21 / 1215) \\
3.9 \%(3 / 77) \\
2.0 \%(26 / 1292) \\
13.0 \%(10 / 77) \\
1.5 \%(19 / 1292)\end{array}$ & $\begin{array}{l}3.115[1.355-7.161]^{\#} \\
\text { Reference } \\
1.974[0.584-6.672] \\
\text { Reference } \\
10.000[4.475-22.348]^{\#} \\
\text { Reference }\end{array}$ & $\begin{array}{l}\text { I.347 [0.306-5.934] } \\
\text { Reference } \\
7.215[2.898-17.965]^{*}\end{array}$ \\
\hline
\end{tabular}

Notes: ${ }^{\#} \mathrm{P}<0.1 ; * \mathrm{P}<0.05$.

Abbreviation: STD, sexually transmitted disease.

In our study, none of the recruited participants presented with proctitis. This result is different from the previous studies that highlight the association between MG and symptomatic rectal infection. One study described the clinical features of rectal MG infection in MSM group: infected men were more likely to report rectal pain and rectal ulceration, but it is worth noting more than one-third of them were co-infected with $\mathrm{HSV}^{21}$ Men with symptomatic proctitis $(\mathrm{N}=18)$ had higher load of MG than asymptomatic patients $(\mathrm{N}=18)$ (60,000 copies versus 10,744 copies of organism per swab, $\mathrm{p}=0.023) .{ }^{10}$ More clinical observation studies are 
needed to study the relationship between infection and clinical symptoms.

In our study, nearly two-third patients from Guangxi STD clinic did not receive antibiotics that were recommended by National STD Treatment Guidelines. ${ }^{15}$ The primary reason for this is lack of awareness among clinicians to screen for rectal infection in these patients. The other possible reason is there is no mention of therapeutic regimens for rectal $\mathrm{MG}$ in Chinese STD guidelines. ${ }^{15}$ Although there is still not much known about the natural history and clinical consequences of MG infection, rectal infection would transmit from the infected patient to his/her partners by anal intercourse or other contact behavior. It is extremely crucial to formulate guidelines for rectal $\mathrm{MG}$ infection to assist with clinical management. MG-infected patients should be advised to abstain from sex until they finished treatment and had negative tests of cure from these two anatomical sites. $^{22}$

There are some limitations in this study. Firstly, we selected the STD clinics for our study. Most patients who develop proctitis present to the proctology department rather than the STD clinic for treatment. Secondly, there is a recall bias in collecting sensitive information related to sexual behavior such as sexual orientation, number of sexual partners, rectal intercourse behavior, and so on. Next, we would aim to conduct these studies: (1) the follow-up study for untreated rectal MG infection to understand the self-healing nature of this infection and transmission capacity, (2) genotyping and antibiotic resistance testing on MG positive samples from these two anatomic sites to elaborate the relationship between urogenital $\mathrm{MG}$ and rectal $\mathrm{MG}$.

\section{Conclusion}

Rectal MG infection needs more attention among patients attending STD clinics in China. Female STD clinic attendees, homosexual or bisexual patients, and those having urogenital MG infection are the high-risk population for rectal MG infection. Appropriate strategy for rectal MG screening and treatment needs to be developed for these patients in China.

\section{Acknowledgments}

We are grateful for the collaborating STD clinics where this study took place, and the participants of this study for their cooperation. This work was supported by the Chinese
Academy of Medical Sciences Initiative for Innovative Medicine (grant 2016-I2M-3-021).

\section{Disclosure}

The authors report no conflicts of interest in this work.

\section{References}

1. Jensen JS. Mycoplasma genitalium: yet another challenging STI. Lancet Infect Dis. 2017;17(8):795-796. doi:10.1016/S1473-3099 (17)30364-X

2. Sonnenberg P, Ison CA, Clifton S, et al. Epidemiology of Mycoplasma genitalium in British men and women aged 16-44 years: evidence from the third National Survey of Sexual Attitudes and Lifestyles (Natsal-3). Int J Epidemiol. 2015;44(6):1982-1994. doi:10.1093/ije/dyv194

3. Andersen B, Sokolowski I, Østergaard L, Kjølseth Møller J, Olesen F, Jensen JS. Mycoplasma genitalium: prevalence and behavioural risk factors in the general population. Sex Transm Infect. 2007;83(3):237-241. doi:10.1136/sti.2006.022970

4. Baumann L, Cina M, Egli-Gany D, et al. Prevalence of Mycoplasma genitalium in different population groups: systematic review and meta-analysis. Sex Transm Infect. 2018;94(4):255-262. doi:10.1136/ sextrans-2017-053384

5. Li Y, Su X, Le W, et al. Mycoplasma genitalium in symptomatic male urethritis: macrolide use is associated with increased resistance. Clin Infect Dis. 2020;70(5):805-810. doi:10.1093/cid/ciz294

6. Taylor-Robinson D, Jensen JS. Mycoplasma genitalium: from Chrysalis to multicolored butterfly. Clin Microbiol Rev. 2011;24 (3):498-514.

7. Lis R, Rowhani-Rahbar A, Manhart LE. Mycoplasma genitalium infection and female reproductive tract disease: a meta-analysis. Clin Infect Dis. 2015;61(3):418-426. doi:10.1093/cid/civ312

8. Soni S, Alexander S, Verlander N, et al. The prevalence of urethral and rectal Mycoplasma genitalium and its associations in men who have sex with men attending a genitourinary medicine clinic. Sex Transm Infect. 2010;86(1):21-24. doi:10.1136/sti.2009.038190

9. Read TRH, Murray GL, Danielewski JA, et al. Symptoms, sites, and significance of mycoplasma genitalium in men who have sex with men. Emerg Infect Dis. 2019;25(4):719-727. doi:10.3201/eid2504. 181258

10. Bissessor M, Tabrizi SN, Bradshaw CS, et al. The contribution of Mycoplasma genitalium to the aetiology of sexually acquired infectious proctitis in men who have sex with men. Clin Microbiol Infect. 2016;22(3):260-265. doi:10.1016/j.cmi.2015.11.016

11. Zheng BJ, Yin YP, Han Y, et al. The prevalence of urethral and rectal Mycoplasma genitalium among men who have sex with men in China, a cross-sectional study. BMC Public Health. 2014;14:195. doi: $10.1186 / 1471-2458-14-195$

12. Khosropour CM, Jensen JS, Soge OO, et al. High prevalence of vaginal and rectal Mycoplasma genitalium macrolide resistance among female STD clinic patients in Seattle, Washington. Sex Transm Dis. 2020;47(5):321-325. doi:10.1097/OLQ.00000000000 01148

13. Lillis RA, Martin DH, Nsuami MJ. Mycoplasma genitalium infections in women attending a sexually transmitted disease clinic in New Orleans. Clin Infect Dis. 2019;69(3):459-465. doi:10.1093/cid/ ciy922

14. Jensen JS, Björnelius E, Dohn B, et al. Use of TaqMan $5^{\prime}$ nuclease real-time PCR for quantitative detection of Mycoplasma genitalium DNA in males with and without urethritis who were attendees at a sexually transmitted disease clinic. J Clin Microbiol. 2004;42 (2):683-692. doi:10.1128/JCM.42.2.683-692.2004 
15. Wang QQ, Liu QZ, Xu JH, Eds. Guidelines of Clinical Management of Sexually Transmitted Diseases. Shanghai: Shanghai Science and Technology Press; 2020.

16. Lillis RA, Nsuami MJ, Myers L, et al. Utility of urine, vaginal, cervical, and rectal specimens for detection of Mycoplasma genitalium in women. $J$ Clin Microbiol. 2011;49(5):1990-1992. doi:10.1128/JCM.00129-11

17. Latimer RL, Shilling HS, Vodstrcil LA, et al. Prevalence of Mycoplasma genitalium by anatomical site in men who have sex with men: a systematic review and meta-analysis. Sex Transm Infect. 2020;96(8):563-570. doi:10.1136/sextrans-2019-054310

18. Owen BN, Brock PM, Butler AR, et al. Prevalence and frequency of heterosexual anal intercourse among young people: a systematic review and meta-analysis. AIDS Behav. 2015;19(7):1338-1360. doi:10.1007/s10461-015-0997-y

19. Heijne JCM, van Liere GAFS, Hoebe CJPA, et al. What explains anorectal chlamydia infection in women? Implications of a mathematical model for test and treatment strategies. Sex Transm Infect. 2017;93(4):270-275. doi:10.1136/sextrans-2016-052786
20. Simpson S, Blomfield P, Cornall A, et al. Front-to-back \& dabbing wiping behaviour post-toilet associated with anal neoplasia \& HRHPV carriage in women with previous HPV-mediated gynaecological neoplasia. Cancer Epidemiol. 2016;42:124-132. doi:10.1016/j. canep.2016.04.001

21. Ong JJ, Aung E, Read TRH, et al. Clinical characteristics of anorectal mycoplasma genitalium infection and microbial cure in men who have sex with men. Sex Transm Dis. 2018;45(8):522-526. doi:10.1097/OLQ.0000000000000793

22. Martin DH, Manhart LE, Workowski KA. Mycoplasma genitalium from basic science to public health: summary of the results from a National Institute of Allergy and Infectious Diseases technical consultation and consensus recommendations for future research priorities. J Infect Dis. 2017;216(suppl_2):S427-S430. doi:10.1093/ infdis/jix 147
Infection and Drug Resistance

\section{Publish your work in this journal}

Infection and Drug Resistance is an international, peer-reviewed openaccess journal that focuses on the optimal treatment of infection (bacterial, fungal and viral) and the development and institution of preventive strategies to minimize the development and spread of resistance. The journal is specifically concerned with the epidemiology of
Dovepress

antibiotic resistance and the mechanisms of resistance development and diffusion in both hospitals and the community. The manuscript management system is completely online and includes a very quick and fair peerreview system, which is all easy to use. Visit http://www.dovepress.com/ testimonials.php to read real quotes from published authors. 